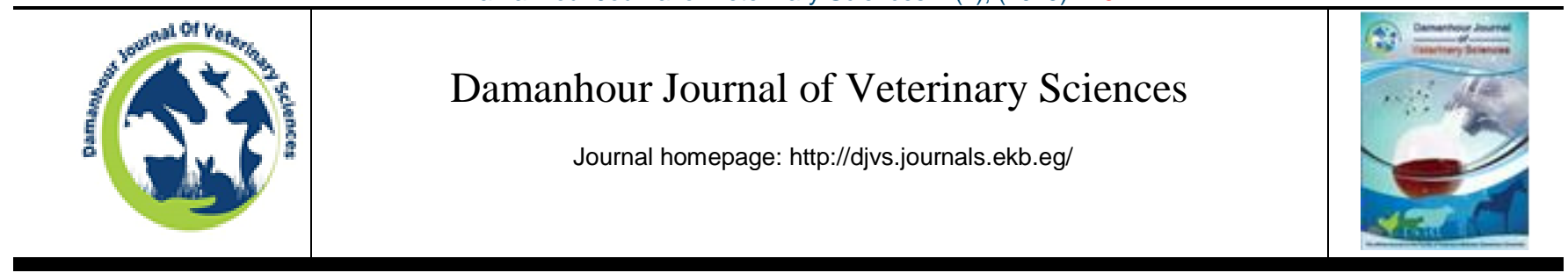

\title{
Genetic Analysis of Highly Pathogenic Avian Influenza H5N1 in West Delta Governorate
}

\author{
H.9qag, S.Y., Abd El-Hamid ${ }^{1}$, H.S., Arafa, A.M., Ellakany, H.F. ${ }^{1}$, Elbestawy, A.R. ${ }^{1 . *}$, Abd Salaheldin, \\ Gado, A.R. ${ }^{1}$ \\ ${ }^{1}$ Department of Poultry and Fish Diseases, , Faculty of Veterinary Medicine, Damanhour University
}

\begin{abstract}
A B S T R A C T
Avian influenza viruses became widely distributed in most Middle Eastern countries, causing high mortality rate and severe economic losses in poultry industry especially when complicated with other pathogens. The continuous evolution of highly pathogenic H5N1 avian influenza viruses (HPAI- H5N1) has resulted in multiple diverse groups based on their haemagglutinin (HA) sequences. In this study, samples from 40 broiler chicken farms during 2014 - 2017 were screened for HPAI- H5N1 Results showed that 15 flocks $(37.5 \%)$ were positive for HPAI-H5 all of them non vaccinated. Furthermore, full sequencing of $\mathrm{HA}$ and NA gene for 3 isolates isolated during 2017 showed that the viruses were clustered with Egyptian viruses from clade 2.2.1.2 and closely related to viruses from neighboring countries.

Keywords: HPAI; H5N1; HA; NA; Sequencing
\end{abstract}

\section{Introduction}

Avian influenza (AI) viruses are members of the genus influenza virus $\mathrm{A}$ in the family Orthomyxoviridae and possess a single-stranded RNA genome composed of eight gene segments encode at least ten viral proteins (Yoon et al 2014). The two envelope glycoproteins hemagglutinin (HA) and neuraminidase (NA) are responsible for virus attachment to and release from the host cell, respectively. HA is the main determinant of virulence and immunogenicity (Yoon et al 2014).

Based on the haemagglutinin (HA) and neuraminidase (NA), the two main surface transmembrane glycoproteins, there are at least $18 \mathrm{HA}$ and probably 10 NA subtypes. According to their pathogenicity in chickens, AIVs which cause asymptomatic infection are recognized as low pathogenic AIV (LPAIV). Meanwhile those AIVs causing high mortalities are recognized as highly pathogenic AIV (HPAIV) (Tong et al 2012).

The natural reservoir of all avian influenza viruses is wild waterfowl, where they appear to be asymptomatic or show low pathogenicity indicating the evolutionary adaptation of the virus in the host (Horimoto and Kawaoka, 2001). The introduction of H5 or H7 subtypes of LPAI viruses to susceptible poultry flocks is the basis of a chain of infection events which may lead to the new development of highly pathogenic subtypes. The risk that infection will be transmitted from wild birds to domestic poultry is greatest where domestic birds roam freely, share a water supply with wild birds, or use a water or food supply that might become contaminated by dropping from carriers wild birds (Henzler et al., 2003).

In February 2006, severe outbreaks of HPAIV H5N1 emerged in several Egyptian Governorates and were associated with drastic mortality up to $100 \%$ in infected birds (Aly et al 2006). The Egyptian strains belonged to subclade 2.2 of the H5N1 virus of Eurasian origin, which is also circulating

\section{*Corresponding author:}

E-mail address: ahmed.elbestawy@ vetmed.dmu.edu.eg

Department of Poultry and Fish Diseases, , Faculty of Veterinary Medicine, Damanhour University

\section{P ISSN: 2636-3003 EISSN: 2636-3011}

Received: Juky 28, 2019; Received in revised form: August 5, 2019; accepted: August 8, 2019. in the Middle East region. Genetic and antigenic analysis of the circulating field viruses in vaccinated flocks revealed subtype antigenic variation and antigenic drift of the virus in comparison to vaccine strains (Abdelwhab et al 2012 b).

These mutations allowed the virus to evade the receptor of host immune responses after vaccination (Cattoli et al 2011). Studies have reported that stable lineages of $\mathrm{H} 5 \mathrm{~N} 1$ viruses are found in vaccinated chickens and humans in Egypt (Abdelwhab et al 2011). Two different H5N1 groups of viruses are currently co- circulating in Egypt referred to as classic strains 2.2.1 which is usually isolated from backyard birds (rarely from vaccinated small commercial farms) and humans and variant strains 2.2.1.1 and 2.2.1.2 subclades, isolated from vaccinated and backyard birds, respectively (Abdelwhab 2012-a).

The diversity of viral HA gene found in Egypt (Abdelwhab et al., 2016) may be partially explained by the wide range of poultry production systems coexisting in the Nile River Delta, ranging from backyard and household ownership to large commercial and industrial farms. Each system is associated with specific mixes of domestic species, different levels of biosecurity, differences in vaccine coverage, different production cycles and value chains (Ali et al., 2013) resulting in a wide diversity of selection pressures for the HPAI A (H5N1) virus. Although gallinaceous species dominate the commercial and industrial meat and egg production, ducks, geese, turkeys, pigeons and quails are also intensively reared and are very essential and palatable sources of meat in Egypt. The survival, transmission rate and susceptibility for HPAI A (H5N1) infection varies considerably between poultry species, with notably ducks showing less mortality and clinical signs of infection than chickens, turkeys and geese for the clade 2.2.1.2 circulating in 2014 and 2015 (Kandeil et al., 2017)

Vaccination should only be used as part of a comprehensive control strategy that also includes biosecurity, quarantine, surveillance, eradication and elimination of infected and at-risk poultry. Although properly used potent AI vaccines can prevent disease and death, increase resistance to infection, reduce virus replication and shedding and transmission but they cannot completely prevent AI virus replication. Only inactivated whole AI virus vaccines and recombinant $\mathrm{H} 5$-AI vaccines have been licensed and widely used. AI vaccination programmes should be adapted to local condition to guarantee efficacy and sustainability. Different vaccination performed in endemic areas, emergency vaccination in the face of an epidemic and preventive vaccination whenever a high risk of virus incursion is identified (Marangon et al., 2008).

In endemic area, vaccination of poultry flocks by inactivated or gene vaccines become the only solution in the long-term strategy. Vaccination is targeting to lower losses from mortality, reduce the viral load in the environment and the risk of human infection as well as eradication of positive cases (Lushow et al., 2001)

This study was planned to (1) Study the prevalence of AI viruses H5N1 among broiler chicken farms in west delta during 2014-2017 using (rRTPCR). (2) Sequence analysis of full gene of Haemagglutinin (HA) and Neuraminidase (NA) glycoproteins of HPAI H5N1.

2. Material and methods

2.1. Specimens

Samples were collected from 40 broiler chicken flocks (from 4 Egyptian governorates in West Delta) suspected to be infected with AIV during period from Jan., 2014 to May, 2017 (Table 1). Tissue samples 
included trachea and lung. Out of the examined flocks, only 12 were vaccinated against HPAIV while 28 flocks were non-vaccinated.

Table 1: History of positive broiler chicken flocks for HPAI- H5N1

\begin{tabular}{|c|c|c|c|c|c|c|}
\hline Serial no. & Location & Sampling date & Total No. & Age (days) & Vaccination against $\mathrm{H5}$ & Mortality during the week of sampling \\
\hline 1 & El-Behera* & Mar. 2017 & 3000 & 32 & \multirow{15}{*}{ Non vaccinated } & $42 \%$ \\
\hline 2 & El-Behera & Mar. 2017 & 3500 & 29 & & $35 \%$ \\
\hline 3 & $\begin{array}{c}\text { Kafer } \\
\text { Elsheikh }\end{array}$ & Mar. 2017 & 2500 & 26 & & $46 \%$ \\
\hline 4 & $\begin{array}{c}\text { Kafer } \\
\text { Elsheikh }\end{array}$ & Mar. 2017 & 3800 & 32 & & $51 \%$ \\
\hline 5 & El-Gharbia & Feb. 2017 & 4200 & 32 & & $52 \%$ \\
\hline 6 & El-Behera & Octo. 2016 & 4000 & 18 & & $60 \%$ \\
\hline 7 & El-Behera & Jan. 2016 & 4500 & 25 & & $24 \%$ \\
\hline 8 & Alexandria & Mar. 2016 & 3000 & 19 & & $47 \%$ \\
\hline 9 & Elgharbia & Mar. 2016 & 2800 & 23 & & $55 \%$ \\
\hline 10 & $\begin{array}{c}\text { Kafer } \\
\text { Elsheikh }\end{array}$ & Mar. 2015 & 4300 & 18 & & $32 \%$ \\
\hline 11 & El-Behera & Apr. 2015 & 4500 & 29 & & $40 \%$ \\
\hline 12 & El-Gharbia & May. 2015 & 3000 & 15 & & $51 \%$ \\
\hline 13 & El-Behera & Mar. 2014 & 3500 & 20 & & $42 \%$ \\
\hline 14 & Alexandria & Mar. 2014 & 4500 & 27 & & $44 \%$ \\
\hline 15 & El-Behera & Feb. 2014 & 3000 & 22 & & $53 \%$ \\
\hline
\end{tabular}

Table 2: Primers used in this study

\begin{tabular}{|c|c|c|}
\hline Virus & Primer and Probe Sequences & Reference \\
\hline AI type A (matrix gene) & $\begin{array}{l}\text { Sep1: 5- AGA TGA GTC TTC TTA CCG AGG TCG-3 } \\
\text { Sep2: 5-TGA AAA AAC ATC TTC AAG TCT CTG3- } \\
\text { SEPRO: 5- } 6 \text {-FAM }\} \text {-TCA GGC CCC CTC AAA GCC GA \{TAMRA\} }\end{array}$ & Spackman et al., 2002 \\
\hline H5N1 & $\begin{array}{l}\text { H5 LH1: 5-ACATATGACTACCCACARTATTCAG-3 } \\
\text { H5 RH1: 5-AGACCAGCTAYCATGATTGC-3 } \\
\text { H5 PRO: [FAM] 5-TCAGGCCCCCTCAAAGCCGA-3 [TAMRA] }\end{array}$ & Löndt et al., 2008 \\
\hline H9N2 & $\begin{array}{l}\text { H9F: 5' GGAAGAATTAATTATTATTGGTCGGTAC '3 } \\
\text { H9R: 5' GCCACCTTTTTCAGTCTGACATT'3 } \\
\text { H9PRO: FAM-5 AACCAGGCCAGACATTGCGAGTAAGATCC-3 } \\
\text { TAMRA }\end{array}$ & Ben Shabat et al. 2010 \\
\hline NDV matrix protein & $\begin{array}{l}\text { MF 5' AGTGATGTGCTCGGACCTTC '3 } \\
\text { MR5' CCTGAGGAGAGGCATTTGCTA '3 } \\
\text { Probe [FAM] 5- TTCTCTAGCAGTGGGACAGCCTGC -3 [TAMRA] }\end{array}$ & Wise et al. 2004 \\
\hline IBV & $\begin{array}{l}\text { XCE3: F 5'CAGATTGCTTACAACCACC '3 } \\
\text { BCE1: F 5'AGTAGTTTTGTGTATAAACCA '3 } \\
\text { DCE1: F 5'ATACAATTATATCAAACCAGC '3 } \\
\text { MCE1: R 5'AATACTACTTTTACGTTACAC }\end{array}$ & Adzhar et al. 1997 \\
\hline
\end{tabular}

Table 3: History of AIV H5N1isolates selected for sequencing.

\begin{tabular}{|c|c|c|c|c|c|c|c|}
\hline Flock no. & Code no. & Seq. code & Species & Location & Date & Subtype & Mortality \% \\
\hline 1 & 1 & B1 & Broiler & Behera & Mar.2017 & H5N1 & $42 \%$ \\
\hline 2 & 2 & B11 & Broiler & Behera & Mar.2017 & $\mathrm{H} 5 \mathrm{~N} 1$ & $35 \%$ \\
\hline 3 & 5 & G15 & Broiler & Gharbia & Feb. 2017 & H5N1 & $52 \%$ \\
\hline
\end{tabular}




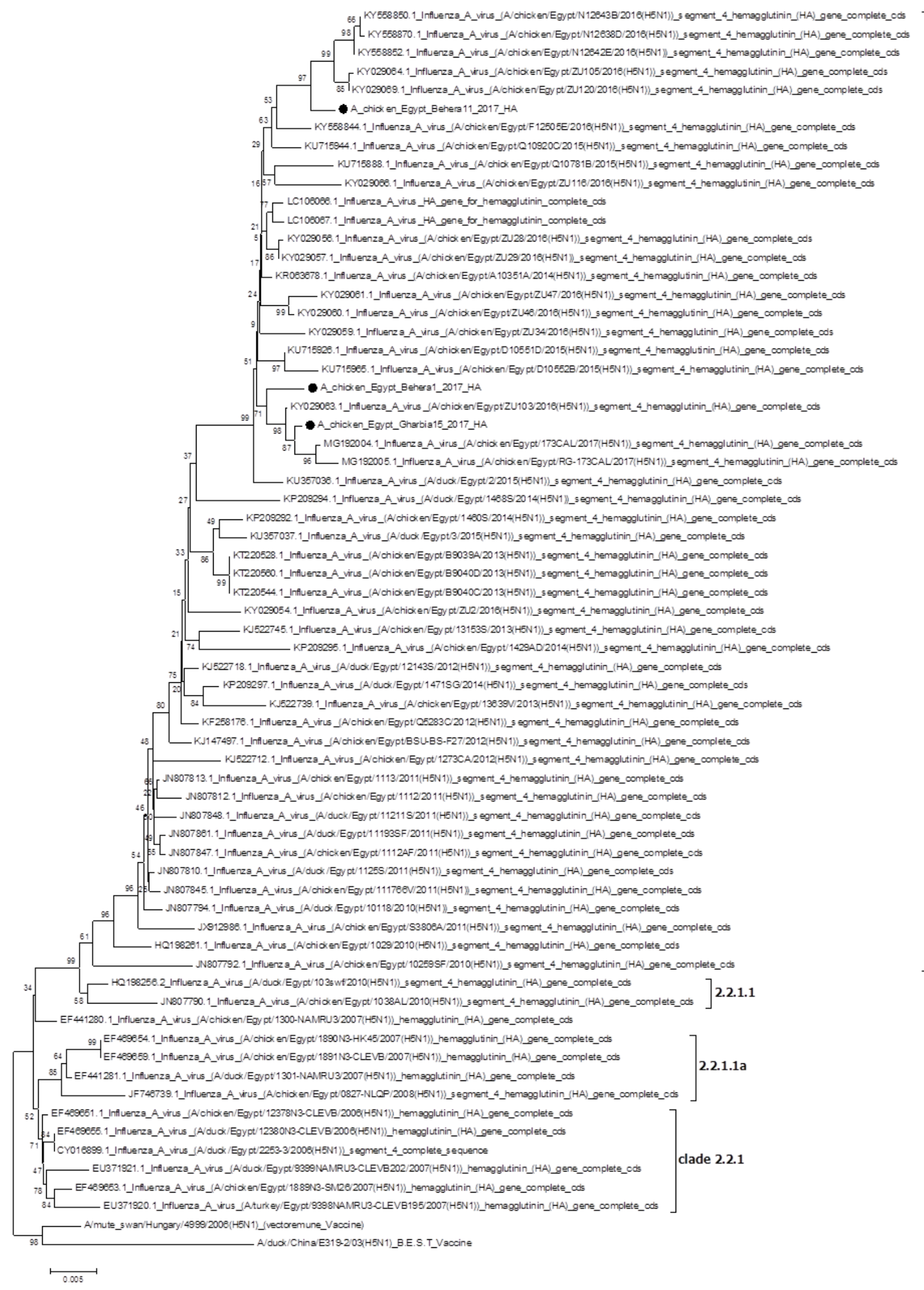

Figure 1: Phylogenetic tree showing the genetic relationships between representative HPAI (H5N1) and 3 isolates of 2017 for HA gene 


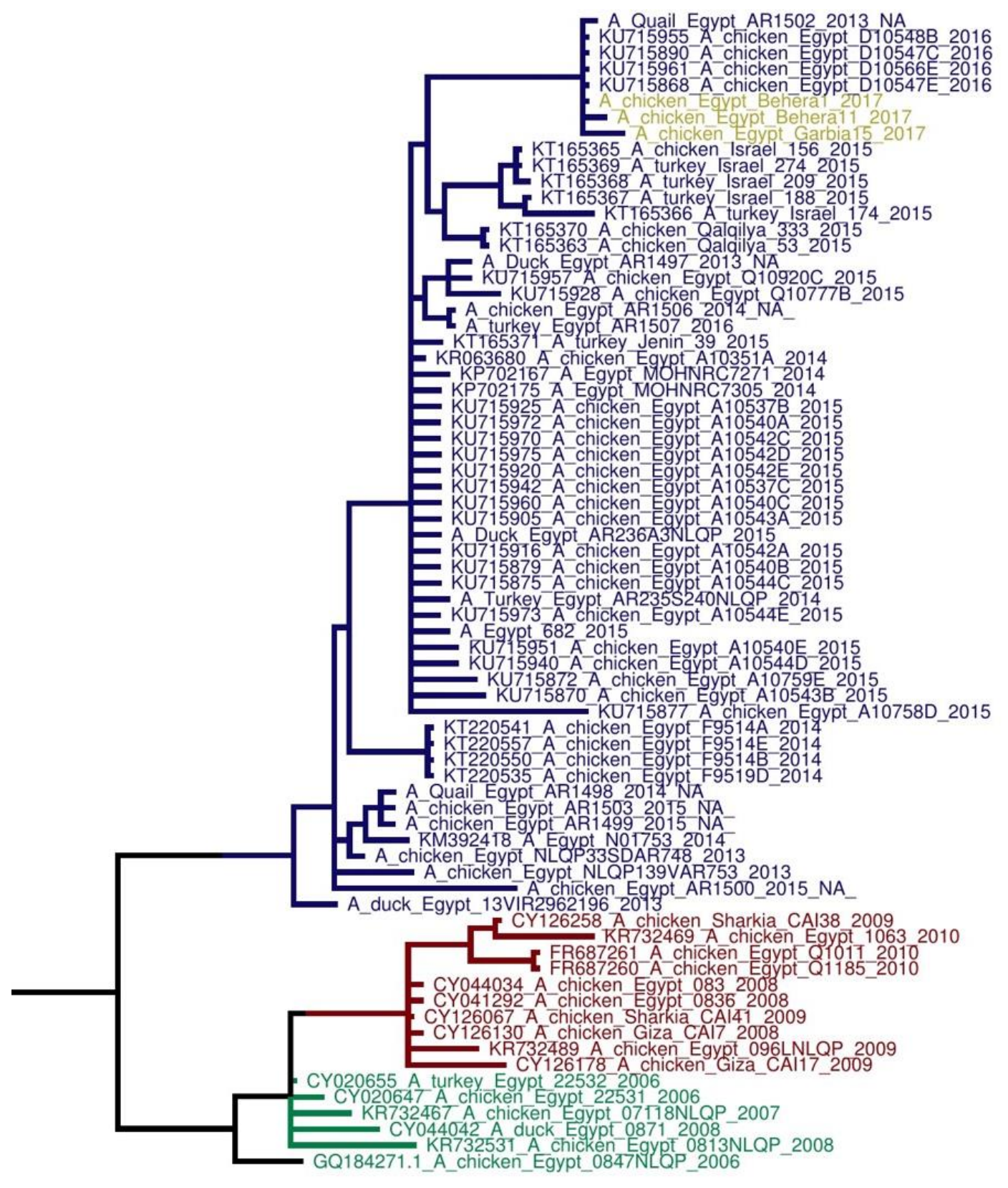

0.0030

Figure 2: Phylogenetic tree showing the genetic relationships between representative HPAI (H5N1) and 3 isolates of 2017 for NA gene.

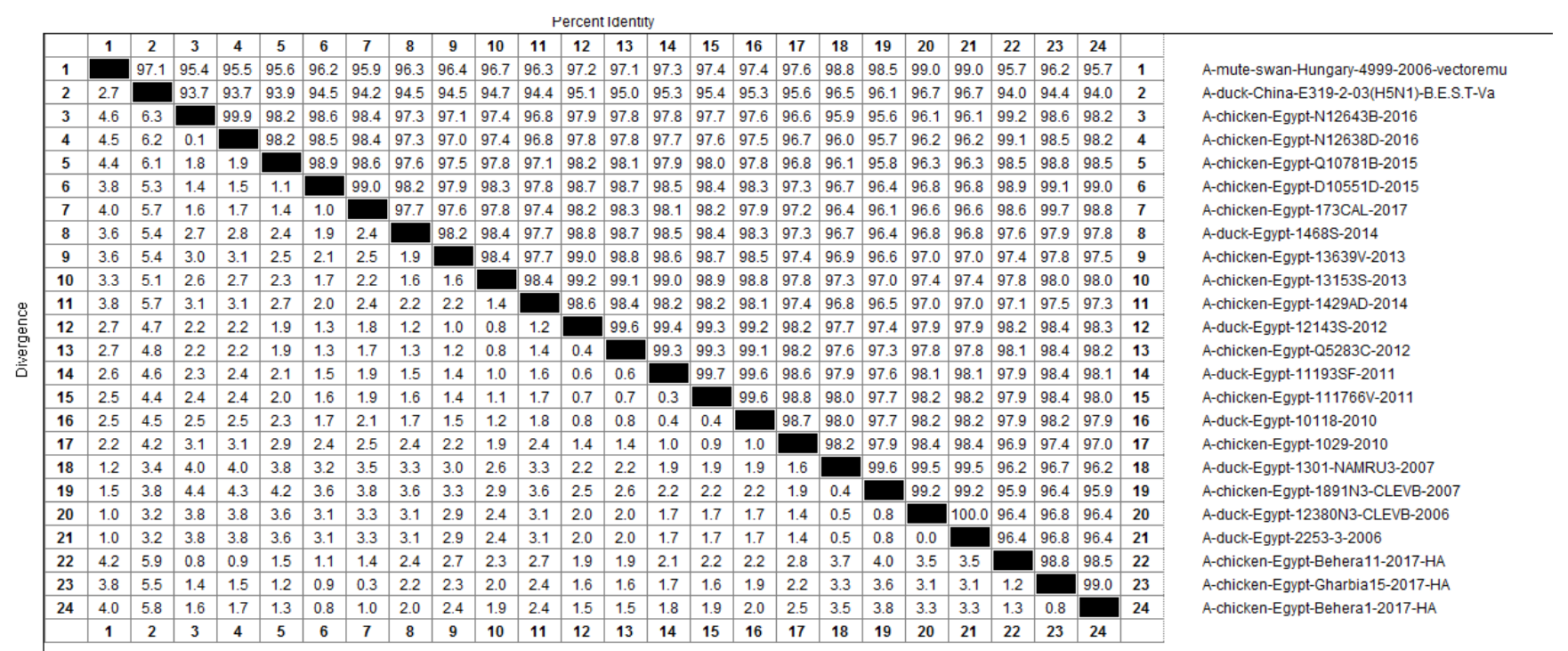

Figure 3: Amino acid identity of the 3 sequenced HPAI H5N1 isolates. 


\subsection{Virus isolation}

Virus isolation and propagation was carried out on 75 Specific Pathogen Free Embryonated Chicken Eggs (SPF-ECE) through allantoic inoculation (9-11 day old), then incubated at $37{ }^{\circ} \mathrm{C}$ for $3-5$ days for the positive flocks only. The harvested allantoic fluids were tested for virus haemagglutination activity by HA assay (OIE, 2015).

2.3. Real Time Reverse Transcriptase Polymerase Chain Reaction (rRT$P(R)$ :

QIAamp® viral RNA mini kit (Cat. No. 52904, Qiagen, Germany) was used to allow extraction of viral RNA from positive HA allantoic fluid samples as described by manufacturer manual of Qiagen RNA extraction kit (Spackman et al., 2002). Specific rRT-PCR primers as type A (Matrix gene), H5 were used for virus identification as mentioned by (Löndt et al., 2008) as well as detection of NDV, LPAI (H9N2), and IBV using specific primers (Table2).

2.4. Sequencing and sequence analysis of HPAI-H5 isolates

Three H5N1 isolates were selected for full HA and NA sequencing. Total RNA extraction using Qiampviral RNA mini Kit (Qiagen USA) according to the manufacturer's instructions of the kit. Sequencing was performed using Applied Biosystems 3130 genetic analyzer, USA. Sequence similarity to each gene segment of the virus isolated in this study was conducted by Basic Local Alignment Search Tool (BLAST) database available at the NCBI (Altschul et al., 1990). The phylogenetic analysis was done by using maximum likelihood (ML) tree method by Mega 6 software (Tamura et al., 2013)

\section{Results and Discussion}

A total number of 15 out of 40 commercial broiler flocks were identified as HPAI-H5 positive by rRT-PCR using type A and H5. All the positive isolates were obtained from non-vaccinated flocks against H5N1. Only 3 samples (No 4, 6, and 11) out of the 15 were positive isolates for each of LPAI-H9N2, NDV or IBV viruses, respectively, using specific primers

Endemic HPAI H5N1 subclade 2.2.1.2 strains from Egypt in 2014, 2015 and 2016 regarding both genes (Fig. $1 \& 2$ ). The amino acid identities $\%$ of the selected isolates ranged from 95.4 to 98.2 with the Egyptian isolates from 2005 and 2016, respectively (Fig. 3).

The Egyptian $\mathrm{H} 5 \mathrm{~N} 1$ viruses have undergone significant antigenic diversification and the antigenic diversity of these viruses may represent a potential challenge for the development of an effective vaccination program for poultry in Egypt (Beato et al., 2013).

Therefore, more efforts are required to better understand changes in the evolution and epidemiology of the virus. Constant monitoring for the possible emergence of resistant variants and rigorous evaluation of the potency of vaccines against Egyptian strains of H5N1 is essential to effectively control the disease in poultry. Ideally, this should be conducted frequently either annually or biannually under representative field condition (Abdelwhab et al., 2012a).

From this point of view, we detected the endemic HPAI- H5N1 subclade 2.2.1.2 virus in broiler chicken flocks in the Egyptian West Delta during 2014-2017. Concerning the rRT-PCR results, HPAI- H5N1 was detected in 15 out of 40 examined broiler flocks $(37.5 \%)$ with a mortality rate ranged from $24-60 \%$. All positive flocks were non vaccinated agains AIV- H5. One third of the isolates was during 2017 and the remaining 2/3 were during 2014-2016 which indicate an increase in the incidence of the disease. Also, it was noticed that $60 \%(9 / 15)$ of the strains were collected during March, isolates no. (1-4) during 2017, (8, 9) during 2016, (10) during 2015, and $(13,14)$ during 2014 indicating the high incidence of HPAI- H5N1 subclade 2.2.1.2 during this month of the year. These results matched with those of WHO (2010) and in accordance to the national veterinary services who declared that $\mathrm{H} 5 \mathrm{~N} 1$ became endemic in Egypt resulting in severe losses in the poultry industry. On other hand, Abd ElHamid et al. (2017) reported that HPAI- H5N1 isolated in Upper Egyp from January 2015 to January 2016 with a percentage of $21.3 \%$ with the highest incidence during the winter season with a mortality rate ranged from $10-25 \%$

Full HA and NA gene sequencing for the 3 isolates of 2017 have a close relation with HPAI- H5N1 strains to the genetically diverse classical endemic subclade 2.2.1.2 from Egypt during 2014, 2015 and 2016 regarding both genes. Previously, partial haemagglutinin (HA) gene sequencing for 5 isolates of HPAI-H5N1 from Upper Egypt during 2015 2016 revealed that all strains were clustered with H5N1 viruses to subclade 2.2.1.2 of Eurasian origin which is also circulating in the Middle East region and was introduced into Africa since 2008. This indicated the predominance of this clade (Abd El-Hamid et al., 2017). Although the dominant clade from 2006 till 2014 was 2.2.1, the analysis of virus population dynamics of the entire data set of the Egyptian H5N1 viruses showed a rise in genetic diversity in the 2.2.1.2 cluster from early 2008 From 2009 to 2014 , the 2.2.1.2 cluster exhibited a constant progressive adaptation to poultry environment and was considered to be an endemic cluster. This endemic clade 2.2.1.2 showed a high evolution rate and this reflects the continuous adaptation of Egyptian viruses to the poultry and to their environment with persistent changes every season (El-Shesheny et al. 2014; Arafa et al., 2016; Kayali et al., 2016).

In conclusion, continuous circulation of HPAI subtype H5N1 of clade 2.2.1.2 specially in non-vaccinated commercial and backyard flocks resembles a ring alarm threatens the poultry industry in the next years. Vaccination using a matched clade prepared vaccine is very important to control the disease spreading.

\section{Conflict of interests}

The authors have not declared any conflict of interests.

\section{References}

Abd El-Hamid, H.S., Ellakany,H.F., Elbestawy, A.R., Abd Elkader, MA. 2017. Highly Pathogenic Avian Influenza H5N1 in Chickens in Upper Egypt. Zagazig Vet. J. 45 (4): 376-385.

Abdelwhab, E.M, Hassan, M.K., Abdel-Moneim, A.S., Naguib, M.M, Mostafa, A., Hussein, I.T.M. 2016. Introduction and enzootic of a/H5N1 in Egypt: virus evolution, pathogenicity and vaccine efficacy ten years on. Infect. Gen. Evol. 40: 80-90.

Abdelwhab, E.M., Arafa, A.S., Stech, J., Grund, C., Stech, O., GraeberGerberding, M., Beer, M., Hassan, M.K., Aly, M.M., Harder. T.C. 2012 a. Diversifying evolution of highly pathogenic H5N1 avian influenza virus in Egypt from 2006 to 2011. Virus Genes 45:14-23.

Abdelwhab, E.M., Grund, C., Aly, M.M., Beer, M., Harder, T.C. Hafez, H.M. 2011. Multiple dose vaccination with heterologous $\mathrm{H} 5 \mathrm{~N} 2$ vaccine: immune response and protec-tion against variant clade 2.2.1 highly pathogenicavian influenza $\mathrm{H} 5 \mathrm{~N} 1$ in broiler breeder chickens. Vaccine 29: 6219-6225.

Abdelwhab, E.M., Grund, C., Aly., M.M., Beer, M.; Harder.,T.C., Hafez, H.M. 2012b. Iinfuence of maternal immunity on vaccine efficacy and susceptibility of one day old chicks against Egyptian highly pathogenic avian influenza H5N1. Vet. Microbiol. 155, 13-20.

Adzhar, A., Haydon, D., Shaw, K.; Britton, P. \& Cavanagh, D. (1997): Molecular analysis of the 793/B serotype of infectious bronchitis virus in Great Britain. Avian Patho., Volume 26, Issue 3.

Ali, A.M., Ankers, P., DeHaan, N., Saad, A., Hussein, S., Lubroth, J. 2013. Mapping influenza A (H5N1) virus transmission pathways and critical control points in Egypt. Food and Agriculture Organization of the United Nations.

Altschul, S.F., Gish, W., Miller, W., Myers, E.W., Lipman, D.J. 1990. Basic local alignment search tool. J. Mol. Biol. 215:403-10

Aly, M. M., Hassan, M. K., Arafa, A. 2006. Emergence of highly pathogenic H5N1 avian influenza virus in poultry in Egypt. First record of 2006 outbreaks. J. Egy. Vet. Med. Assoc., 66(2): 263-276.

Arafa, A., El-Masry, E., Kholosy, S., Hassan, M.K., Dauphin, G., Lubroth, J., Makonnen, Y.J. 2016. Phylodynamics of avian influenza clade 2.2.1 H5N1 viruses in Egypt. Virol. J. 13: 49-60.

Beato, M.S., Mancin, M., Yang, J., Buratin, A., Ruffa, M., Maniero, S., Fusaro, A., Terregino, C., Wanc, X., Capua, I 2013. Antigenic characterization of recent $\mathrm{H} 5 \mathrm{~N} 1$ highly pathogenic avian influenza viruses circulating in Egyptian poultry. Virology 435: 350-356.

Ben Shabat, M., Meir, R., Haddas, R., Lapin, E., Shkoda, I., Raibstein, I., Perk, S., Davidson, I. 2010. Development of a real-time TaqMan RT-PCR assay for the detection of H9N2 avian influenza viruses. J. Virol. Methods 168 (1-2): 72-7.

Cattoli, G., Fusaro, A., Monne, I., Coven, F., Joannis, T., El-Hamid, H.S., Hussein, A.A., Cornelius, C., Amarin, N.M., Mancin, M. 2011. Evidence for differing evolutionary dynamics of $\mathrm{A} / \mathrm{H} 5 \mathrm{~N} 1$ viruses among countries applying or not applying avian influenza vaccination in poultry. Vaccine 29: 9368-9375.

El-Shesheny, R., Kandeil, A., Bagato, O., Maatouq, A.M., Moatasim, Y., Rubrum, A., Song, M., Webby, R.J., Ali, M.A., Kayali, G. 2014. Molecular characterization of avian influenza H5N1 virus in Egypt and the emergence of a novel endemic subclade. J. General Virol. 95, 1444-1463. Henzler, D.J., Kradel, D.C., Davison, S., Ziegler, A.F., Singletary, D., DeBok, P., Castro, A.E., Lu, H., Eckroade, R., Swayne, D., Lagoda, W., Schmucker, B., Nesselrodt, A. 2003. Epidemiology, production losses and control measures associated with an outbreak of avian influenza subtype H7N2 in Pennsylvania (1996-98). Avian Dis. 47: 1022-1036

Horimoto, T., Kawaoka, Y., 2001. Pandemic threat posed by avian influenza A viruses. Clin. Microbiol. Rev. 14 (1): 129-149.

Kandeil, A; Mostafa, A; El-Shesheny, R; El-Taweel, A.N; Gomaa, M. and Galal, H. (2017): Avian influenza H5N1 vaccination efficacy in Egyptian backyard poultry. Vaccine, 35: 6195-6201.

Kayali, G., Kandeil, A., El-Shesheny, R., Kayed, A.S., Maatouq, A.M., Cai, Z., McKenzie, P.P., Webby, R.J., El Refaey, S., Kandeel, A., Ali, M.A. 2016. Avian Influenza A (H5N1) Virus in Egypt. Emerg. Infect. Dis. 22 (3): 379-388. 
Lushow, D., Werner, O., Mettenleiter, T.C., Fuchs, W. 2001. Protection of chickens from leathal avian influenza A virus infection by live-virus vaccination with infectious laryngotracheitis virus recombinants expressing the hemagglutinin (H5) gene. Vaccine 19(30): 4249-4259.

Löndt, B.Z, Nunez, A., Banks, J., Nili, H., Johnson, L.K., Alexander, D.J. 2008. Pathogenesis of highly pathogenic avian influenza A/turkey/Turkey /1/2005 H5N1 in Pekin ducks (Anas platyrhynchos) infected experimentally. Avian Pathol. 37(6): 619-627.

Marangon, S., Cecchinato, M., Capua, I. 2008. Use of vaccination in avian influenza control and eradication. Zoonoses Public Health 55 (1): 65-72.

OIE Manual 2015. Available at: http://www.oie.int/ fileadmin/Home /fr / Health_standards/tahm/2.03.04_AI.pdf avian influenza Chapter 2.3.4.
Spackman, E., Ip, H.S., Suarez, D.L., Slemons, R.D., Stallknecht, D.E. 2002. Analytical validation of a real-time reverse transcription polymerase chain reaction test for Pan-American lineage H7 subtype Avian influenza viruses. J. Vet. Diagn. Invest. 20: 612-616.

Tamura, K., Stecher, G., Peterson, D., Filipski, A., Kumar, S. 2013. MEGA6: molecular evolutionary genetics analysis version 6.0. Mol. Biol. Evol. 30: 2725-2729.

Tong. S., Li,Y., Rivailler, P. 2012. A distinct lineage of influenza A virus from bats. P.N.A.S. 109:4269-427.

Yoon, S. W., Webby, R.J., Webster, R.G. 2017. Evolution and ecology of influenza A viruses. Curr. Top. Microbiol. Immunol. 385:359-75. 